\title{
Capillary Liquid Chromatography with UV Detection Using $N, N$-Diethyl Dithiocarbamate for Determining Platinum-Based Antitumor Drugs in Plasma
}

\author{
Yasutaka Otsuki, Akira Kotani,* and Fumiyo Kusu \\ Department of Analytical Chemistry, School of Pharmacy, Tokyo University of Pharmacy and Life Sciences; 1432-1 \\ Horinouchi, Hachioji, Tokyo 192-0392, Japan. \\ Received November 17, 2011; accepted February 20, 2012; published online February 22, 2012
}

A capillary liquid chromatography with UV detection (CLC-UV) system has been developed for determining platinum-based antitumor drugs (e.g., cisplatin, carboplatin, and nedaplatin) in plasma based on the pre-column derivatization of platinum with $N, N$-diethyl dithiocarbamate (DDTC). The chelated platinum separation was carried out on a capillary column (Inertsil ODS-3, $150 \mathrm{~mm} \times 0.3 \mathrm{~mm}$ i.d., $3 \mu \mathrm{m}$ ) using an acetonitrile-water mixture $(8: 2, \mathrm{v} / \mathrm{v})$ as a mobile phase that flowed at $5.0 \mu \mathrm{L} / \mathrm{min}$. Detection was carried out by absorbance at $254 \mathrm{~nm}$. Chromatographic peak height was found to be linearly related to the spiked concentration of nedaplatin in the blank control plasma from $5.0 \mathrm{ng} / \mathrm{mL}$ to $15 \mu \mathrm{g} / \mathrm{mL}\left(r^{2}>0.998\right)$. The repeatability $(n=5)$ of the chromatographic peak height for $2.5 \mu \mathrm{g} / \mathrm{mL}$ nedaplatin was $2.6 \%$ relative standard deviation (R.S.D.). The CLC-UV system, which required only $20 \mu \mathrm{L}$ of plasma sample, was applied to the determination of total and free form platinum-based antitumor drugs in plasma after injection into rats. The recovery rates $(n=5)$ of total and free form nedaplatin in plasma were $98 \%$ and $99 \%$, respectively, and these repeatability were $2.4 \%$ R.S.D. and $3.1 \%$ R.S.D., respectively. In addition, the recovery rates $(n=5)$ of total and free form carboplatin in plasma were $99 \%$ and $99 \%$, respectively, and these repeatability were $2.9 \%$ R.S.D. and $0.24 \%$ R.S.D., respectively. The concentration-time profiles of total and free form nedaplatin in rat plasma were monitored to determine the pharmacokinetic parameters.

Key words platinum-based antitumor drug; plasma; capillary column; liquid chromatography

Platinum-based antitumor drugs, including cisplatin, carboplatin, oxaliplatin, and nedaplatin are used to treat various types of cancers, such as sarcomas, carcinomas, etc. Nedaplatin, cis-diammineglycolatioplatinum, is a second-generation platinum agent that is approximately 10 times as soluble in water as cisplatin. ${ }^{1-4)}$ As such, nedaplatin is considered to have more pronounced activity against solid tumors, but less nephrotoxicity and gastrointestinal toxicity than cisplatin. ${ }^{1)}$ However, severe bone marrow suppression is one of its important adverse effects, as such analyses of efficacy and safety are needed for clinical usage. ${ }^{5)}$ In pharmacokinetic studies of platinum-based antitumor drugs, atomic absorption spectroscopy (AAS) ${ }^{6,7)}$ and HPLC with UV detection (HPLC-UV) ${ }^{8-10)}$ have been commonly utilized. Further, as a sensitive method for determining the platinum agent in plasma, non-flame atomic absorption spectrometry (NFAAS), inductively coupled plasma with atomic emission spectrometry (ICP-AES), and ICP with mass spectrometry (ICP-MS) have been widely used in various fields. ${ }^{11-22)}$ In these spectrometric techniques, only NFAAS was applied to determine nedaplatin in plasma. The accuracy and precision of NFAAS, ICP-AES, and ICP-MS, however, is highly dependent on the sample matrix from biological samples. In addition to the complicated sample preparation and cleanup procedures, ICP-AES and ICP-MS require expensive equipment and have high running costs. A simple and sensitive method for the therapeutic drug monitoring (TDM) of platinum-based antitumor drugs has been desired to minimize their side effects of nephrotoxicity, neurotoxicity, and ototoxicity.

An HPLC-UV of platinum-based antitumor drugs is widely used after derivatization with a chromophore in biomedical analysis. Although a determination method of plasma agent by HPLC-UV is highly desirable from a practical viewpoint, the sample sizes reported were $0.1-6 \mathrm{~mL}$, and thus the detection limit was about $0.1 \mu \mathrm{g} / \mathrm{mL} .^{23-26)}$ The chromatographic sensitivity of liquid chromatography using a capillary column (0.1-0.5 mm i.d.), i.e. capillary liquid chromatography (CLC) would be expected to be superior to that of HPLC. ${ }^{27,28)}$ Thus, in this study, we will propose a high-sensitive determination method of plasma platinum-based antitumor drugs by CLC with UV detection (CLC-UV). Additionally, the volume of mobile phase in CLC is lower than that in HPLC and thus would be ideal as an analytical method for TDM from the points of view of economical efficiency and green chemistry.

In this study, we developed a method for the determination of platinum-based antitumor drugs in plasma by a CLC-UV system subsequent to derivatization using $N, N$-diethyl dithiocarbamate (DDTC) to form a chelate complex with platinum. The determination of free and total nedaplatin and carboplatin in plasma were individually carried out by the CLC-UV, and then the pharmacokinetic parameters of free and total nedaplatin in plasma were obtained using each time-concentration profile.

\section{Experimental}

Reagents Nedaplatin (>99\%) was obtained from LKT Laboratories (Saint Paul, MN, U.S.A.). Sodium N,N-diethyl dithiocarbamate trihydrate (DDTC), acetonitrile (>99.8\%, HPLC grade), nickel chloride, carboplatin ( $>99 \%$ ), iron(III) chloride $\left(\mathrm{FeCl}_{3},>98 \%\right)$, copper(II) chloride $\left(\mathrm{CuCl}_{2},>98 \%\right)$, magnesium chloride $\left(\mathrm{MgCl}_{2},>98 \%\right)$, calcium chloride $\left(\mathrm{CaCl}_{2}\right.$, $>95 \%$ ), and zinc ( $\mathrm{Zn},>99.9 \%$ ) were purchased from Wako Pure Chemical Industries Ltd. (Osaka, Japan). The analytes were dissolved in saline. $\mathrm{Zn}$ was dissolved in a diluted $\mathrm{HCl}$ solution, and then it was diluted by saline. The water used was distilled and purified with a NANO pure II filtering system 
(Barnstead Co., Ltd., Boston, MA, U.S.A.).

Animals Male Wistar rats (eight weeks old, 230-250g) were purchased from Tokyo Laboratory Animals Science Co., Ltd. (Tokyo, Japan). The protocol for animal use and experimentation was reviewed and approved by the animal ethics committee of Tokyo University of Pharmacy and Life Sciences. After $16 \mathrm{~h}$ fasting, the nedaplatin was dissolved in saline at a dose of $3.0 \mathrm{mg} / \mathrm{kg}$, and was intraperitoneally injected into the rats. Blood samples of each rat were taken before and at $5,10,15,30,45,60,90,120,150$, and $180 \mathrm{~min}$ after injection of nedaplatin. Eighty microliters of blood were drawn from the caudal veins of the rats. Plasma was separated by centrifugation of the heparinized blood and stored at $-30^{\circ} \mathrm{C}$ until analysis.

For the determination of plasma carboplatin, blood specimens were drawn from the cervical vein of rats at $30 \mathrm{~min}$ after intravenous injection of $4.5 \mathrm{mg} / \mathrm{kg}$ carboplatin.

Sample Preparations The sample preparation was carried out with the method by Iwabuchi, et $a l^{26)}$ and modified as described in the following sentences. To determine total nedaplatin in rat plasma, $20 \mu \mathrm{L}$ of rat plasma with $0.9 \mu \mathrm{g}$ nickel chloride as an internal standard (IS) was mixed with $80 \mu \mathrm{L}$ of acetonitrile containing $10 \%$ DDTC, and then this solution was incubated at $60^{\circ} \mathrm{C}$ for $1 \mathrm{~h}$. During this incubation, platinum derived from nedaplatin and nickel from nickel chloride formed each chelate complex with DDTC. ${ }^{8,9)}$ This solution was centrifuged at $9000 \mathrm{~g}$ for $5 \mathrm{~min}$, and then the supernatant was filtered through a membrane filter (pore size: $0.45 \mu \mathrm{m}$, Ultrafree$\mathrm{MC}$, Bedford, MA, U.S.A.) and $0.2-\mu \mathrm{L}$ aliquots were injected into the CLC-UV system. To determine free form nedaplatin in rat plasma, an ultrafiltration was additionally performed at $5000 \boldsymbol{g}$ for $10 \mathrm{~min}$ using a filtration device (Centricut W-20, Kurabo Industries Ltd., Osaka, Japan) before incubation with the DDTC solution. The same procedures were carried out to determine total and free form carboplatin in plasma.

CLC-UV System The present CLC-UV system consisted of a pump (MP-711i, GL Science, Tokyo, Japan), a sample injector (7520, Rheodyne, Cotati, CA, U.S.A.) fitted with a $0.2-$ $\mu \mathrm{L}$ injection loop, a capillary column (Inertsil ODS-3 column, $150 \mathrm{~mm} \times 0.3 \mathrm{~mm}$ i.d., $3 \mu \mathrm{m}$, GL Science), and a UV detector (MU-701, GL Science). An acetonitrile-water mixture $(8: 2$, $\mathrm{v} / \mathrm{v})$ was used as a mobile phase and it flowed at $5.0 \mu \mathrm{L} / \mathrm{min}$ into the CLC system. The column temperature was maintained at $23^{\circ} \mathrm{C}$ using a column oven (CTO-10ASvp, Shimadzu, Kyoto, Japan). The UV detection was accomplished at $254 \mathrm{~nm}$.

\section{Results and Discussion}

Optimization of Experimental Conditions Incubation time to form the DDTC chelate: Because of the weak lightabsorption of the platinum agent, derivatization with a strong chromophore is required before or after column separation for the sensitive UV detection of eluted platinum agents. Several labeling reagents, such as 2-acetylpyridine-4-phenyl3-thiosemicarbazone (APPT) ${ }^{23)} \quad N, N^{\prime}$-bis(salicylidene)-1,2propanediamine $\left(\mathrm{H}_{2} \mathrm{SA}_{2} \mathrm{pn}\right),{ }^{24)}$ and $\mathrm{DDTC}^{25)}$ etc., have been reported to form a chelate complex with platinum for determining cisplatin (cis-diaminedichloroplatinum(II)) by HPLC-UV. The molar extinction coefficient of the Pt(DDTC) $)_{2}$ complex is $4300 \mathrm{~L} \mathrm{~mol}^{-1} \mathrm{~cm}^{-1}$. $)$ The linear ranges of cisplatin using APPT, $\mathrm{H}_{2} \mathrm{SA}_{2} \mathrm{pn}$, DDTC chelates by HPLC-UV were $0.5-10 \mu \mathrm{g} / \mathrm{mL},{ }^{23)}$ $1.0-30 \mu \mathrm{g} / \mathrm{mL},{ }^{24)}$ and $0.2-10 \mu \mathrm{g} / \mathrm{mL},{ }^{25)}$ respectively. DDTC is commercially available as an inexpensive reagent, and the derivatization procedure reported would be facile compared with APPT and $\mathrm{H}_{2} \mathrm{SA}_{2}$ pn. Thus, DDTC was selected for the platinum derivatization to determine nedaplatin and carboplatin in plasma. The optimal incubation time to obtain the DDTC and platinum chelate complex with high-efficiency was examined. The chromatographic peak height of nedaplatin was gradually increased accompanied with an increase in incubation time, and then the peak height was no longer increased over $60 \mathrm{~min}$ of incubation time. Thus, $60 \mathrm{~min}$ was selected as the optimal incubation time.

CLC conditions: The optimization of CLC-UV conditions to determine nedaplatin in plasma was carried out. An examination was made of how the ratio of water to acetonitrile in the mobile phase influenced the separation between nedaplatin and nickel chloride (IS). The larger the content of water, the greater was the separation of these peaks. To determine nedaplatin with adequate resolution and within a short time, a mixture of acetonitrile-water $(8: 2, \mathrm{v} / \mathrm{v})$ was chosen for the most suitable mobile phase. It has been previously reported that human or rat serum contains approximately $0.9-3.0 \mu \mathrm{g} /$ $\mathrm{mL} \mathrm{Fe}$, approximately $0.3-1.1 \mu \mathrm{g} / \mathrm{mL} \mathrm{Cu}$, and approximately $0.8-1.3 \mu \mathrm{g} / \mathrm{mL} \mathrm{Zn}{ }^{29-33)}$ Since those metals each form a chelate with DDTC, the chromatographic peaks for the mixture of DDTC and each metal ion would be observed. To examine the retention time for each metal ion, rat plasma which spiked with $62 \mu \mathrm{g} / \mathrm{mL} \mathrm{Fe}^{3+}, 4.7 \mu \mathrm{g} / \mathrm{mL} \mathrm{Cu}^{2+}, 29 \mu \mathrm{g} / \mathrm{mL} \mathrm{Zn}^{2+}, 0.51 \mathrm{mg} /$ $\mathrm{mL} \mathrm{Mg}^{2+}$, or $0.36 \mathrm{mg} / \mathrm{mL} \mathrm{Ca}^{2+}$ were measured by the present CLC-UV. The mixture of $\mathrm{Fe}^{3+}$ and DDTC gave a peak at $5.5 \mathrm{~min}$, the mixture of $\mathrm{Cu}^{2+}$ and DDTC gave two peaks at $4.3 \mathrm{~min}$ and $10.5 \mathrm{~min}$, and the mixture of $\mathrm{Zn}^{2+}$ and DDTC gave a peak at $7.5 \mathrm{~min}$. In the presence of $0.51 \mathrm{mg} / \mathrm{mL} \mathrm{Mg}^{2+}$ or $0.36 \mathrm{mg} / \mathrm{mL} \mathrm{Ca}^{2+}$, no peak appeared. Thus, it is considered that there were no effects from metals existing in the plasma. The flow rate and column temperature during separation were similarly selected at $5.0 \mu \mathrm{L} / \mathrm{min}$ and $23^{\circ} \mathrm{C}$, respectively, based on the above-mentioned reasons.

CLC-UV for Determining Nedaplatin in Rat Plasma $2.5 \mu \mathrm{g} / \mathrm{mL}$ nedaplatin spiked to a rat plasma without nedaplatin was measured by the present CLC-UV. The retention times of nedaplatin and nickel chloride were 6.8 and $8.1 \mathrm{~min}$, respectively. Although some unknown peaks appeared on the chromatogram of rat plasma without nedaplatin spiked, no peaks were appeared close to the nedaplatin and nickel chloride peaks on the chromatogram as shown in Fig. 1A. The chromatographic peak height was found to be linearly related to the spiked concentration of nedaplatin in the rat plasma from $5.0 \mathrm{ng} / \mathrm{mL}$ to $15 \mu \mathrm{g} / \mathrm{mL}\left(r^{2}>0.998\right)$, i.e., the amount of nedaplatin from $3.3 \mathrm{fmol}$ to $9.9 \mathrm{pmol} /$ column injection $\left(r^{2}>0.998\right)$. The repeatability $(n=5)$ of the chromatographic peak height for $2.5 \mu \mathrm{g} / \mathrm{mL}$ nedaplatin was $2.6 \%$ relative standard deviation (R.S.D.). The intra-day and inter-day precisions of chromatographic peak heights for $2.5 \mu \mathrm{g} / \mathrm{mL}$ nedaplatin were less than $5.0 \%$ R.S.D. The detection limit $(S / N=3)$ for nedaplatin was $1.6 \mathrm{ng} / \mathrm{mL}$. The detection limits for the determination of cisplatin by HPLC-UV was $0.1 \mu \mathrm{g} / \mathrm{mL},{ }^{25)}$ nedaplatin by NFAAS was $0.1 \mu \mathrm{g} / \mathrm{mL}$, ${ }^{11)}$ and saliplatin by ICP-MS was $0.4 \mathrm{ng} / \mathrm{mL},{ }^{20)}$ respectively. Thus, the sensitivity of the present CLC-UV is higher than the reported HPLC-UV and NFAAS methods for determining platinum-based antitumor drugs in plasma.

Determination of Nedaplatin and Carboplatin in Rat 

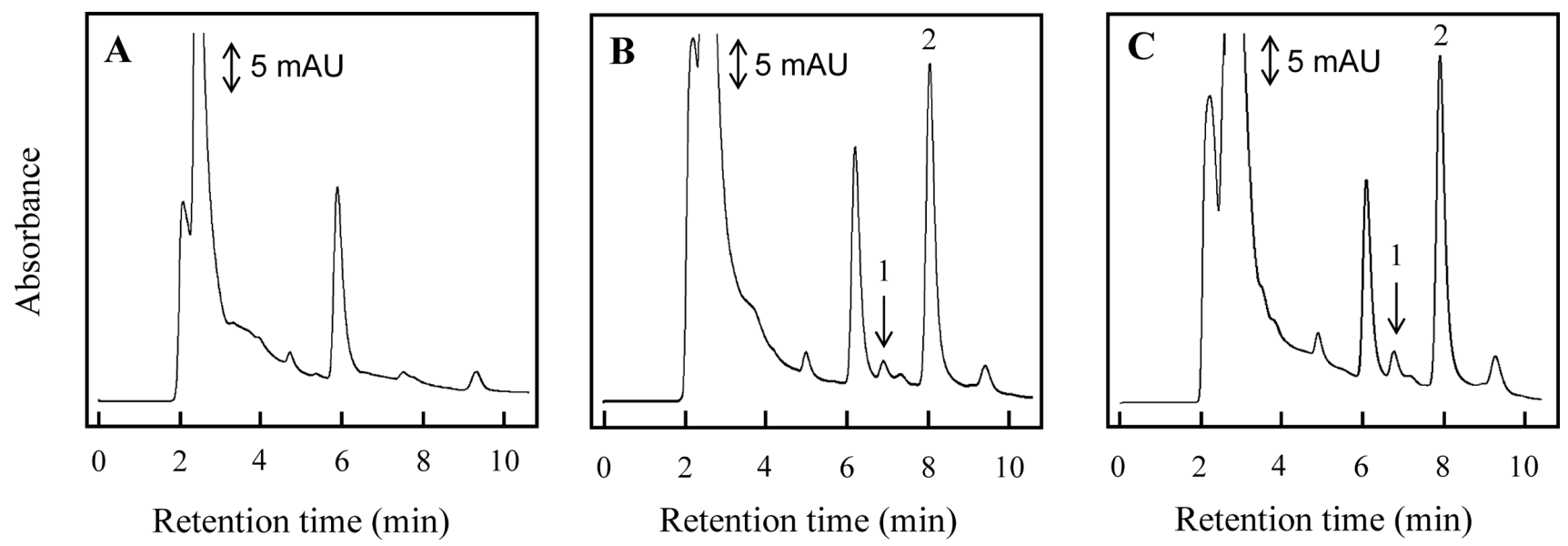

Fig. 1. Chromatogram of Sample Rat Plasma (A) before Injection of Nedaplatin, (B) at 60 min after Intraperitoneal Injection of 3.0 mg/kg Nedaplatin, and (C) Spiked Standard $0.5 \mu \mathrm{g} / \mathrm{mL}$ Nedaplatin in the Sample Rat Plasma of (B)

CLC conditions: mobile phase, acetonitrile-water mixture $(8: 2, \mathrm{v} / \mathrm{v})$; column, Inertsil ODS-3 $(150 \mathrm{~mm} \times 0.3 \mathrm{~mm}$ i.d., $3 \mu \mathrm{m})$; column temperature, $23^{\circ} \mathrm{C}$; wavelength, $254 \mathrm{~nm}$; flow rate, $5.0 \mu \mathrm{L} / \mathrm{min}$. Peaks: 1 , nedaplatin; 2 , nickel chloride (internal standard).

Table 1. Total and Free Platinum-Based Antitumor Drug Concentrations in Rat Plasma and Recovery of Platinum-Based Antitumor Drugs from Plasma Spiked with Their Respective Standard

\begin{tabular}{|c|c|c|c|c|c|c|}
\hline \multirow[b]{2}{*}{ Analyte } & \multirow[b]{2}{*}{ Form } & \multicolumn{2}{|c|}{ Content $(n=5)$} & \multicolumn{3}{|c|}{ Recovery $^{c}(n=5)$} \\
\hline & & $\begin{array}{l}\text { Concentration } \\
(\mu \mathrm{g} / \mathrm{mL})\end{array}$ & R.S.D. (\%) & $\begin{array}{l}\text { Added concentration } \\
(\mu \mathrm{g} / \mathrm{mL})\end{array}$ & Recovery (\%) & R.S.D. (\%) \\
\hline \multirow[t]{2}{*}{ Nedaplatin $^{a)}$} & Total & 0.73 & 4.6 & 0.5 & 98 & 2.4 \\
\hline & Free & 0.54 & 3.7 & 0.5 & 99 & 3.1 \\
\hline \multirow[t]{2}{*}{ Carboplatin $^{b)}$} & Total & 1.1 & 1.5 & 1.5 & 99 & 2.9 \\
\hline & Free & 0.86 & 0.25 & 1.5 & 99 & 0.24 \\
\hline
\end{tabular}

a) Plasma sample obtained from rat at $60 \mathrm{~min}$ after injection of $3.0 \mathrm{mg} / \mathrm{kg}$ nedaplatin. $b$ ) Plasma sample obtained from rat at $30 \mathrm{~min}$ after injection of $4.5 \mathrm{mg} / \mathrm{kg}$ carboplatin. c) For the recovery test, each platinum-based antitumor drug standard was directly spiked to plasma or ultrafiltrated plasma of rat after platinum-based antitumor drug injection. Each the drug derived from both plasma and the standard was extracted to prepare a test solution. The recovery rate of free drug was $100 \%$ when the drug concentration determined was equal to the sum of the drug in the ultrafiltrated plasma and the spiked standard. The recovery rate of total drug was $100 \%$ when the drug concentration determined was equal to the sum of the drug in the plasma and the spiked standard.

Plasma Total and free form nedaplatin levels in rat plasma after intraperitoneal injection were determined using the above-mentioned sample preparation. Figures $1 \mathrm{~B}$ and $\mathrm{C}$ show chromatograms of plasma samples at $60 \mathrm{~min}$ after $3.0 \mathrm{mg} / \mathrm{kg}$ nedaplatin injection and spiked with $0.5 \mu \mathrm{g} / \mathrm{mL}$ standard nedaplatin to plasma sample $60 \mathrm{~min}$ after $3.0 \mathrm{mg} / \mathrm{kg}$ nedaplatin injection, respectively. Total and free form nedaplatin concentrations in rat plasma are listed with their recovery data in Table 1. The repeatability $(n=5)$ of total and free form nedaplatin concentrations in rat plasma were less than $4.6 \%$ R.S.D. The recovery rates $(n=5)$ of nedaplatin for the spiked test solutions were more than $98 \%$ and these repeatability were less than $3.1 \%$ R.S.D. Moreover, total and free carboplatin concentrations in the rat plasma were also determined, and the results are shown in Table 1 . The repeatability $(n=5)$ of total and free form carboplatin concentrations in rat plasma were less than $1.5 \%$ R.S.D. The recovery rates $(n=5)$ of carboplatin for the spiked test solutions were more than $99 \%$ and these repeatability were less than $2.9 \%$ R.S.D. The results demonstrate that the CLC-UV method is characterized by higher reproducibility, indicating that the present CLC-UV method provides accurate measurements of nedaplatin and carboplatin in rat plasma.

Application to Pharmacokinetics Studies The timeconcentration profiles of total and free form nedaplatin concentrations in rat plasma after intraperitoneal injection of

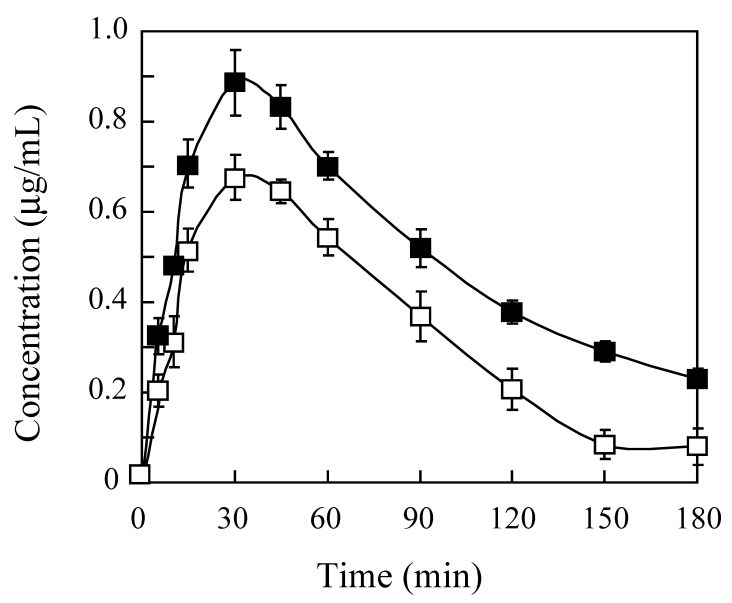

Fig. 2. Time-Concentration Profiles of Mean ( \pm S.E. of Seven Rats)

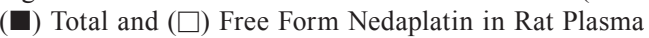

$3.0 \mathrm{mg} / \mathrm{kg}$ of nedaplatin are shown in Fig. 2. Each form of nedaplatin reached a maximum concentration in plasma at about $30 \mathrm{~min}$ after nedaplatin injection, and then both concentrations progressively decreased according to the one-compartment model. Based on the time-concentration profiles, the pharmacokinetic parameters of the total and free nedaplatin were calculated based on the one-compartment model, and 
Table 2. Pharmacokinetic Parameters (Mean \pm S.E. of Seven Rats) of Plasma Nedaplatin after Intraperitoneal Injection of $3.0 \mathrm{mg} / \mathrm{kg}$ Nedaplatin to Rat

\begin{tabular}{lcc}
\hline \hline Parameter $^{a)}$ & Total & Free form \\
\hline$C_{\max }(\mu \mathrm{g} / \mathrm{mL})$ & $0.92 \pm 0.07$ & $0.72 \pm 0.03$ \\
$t_{\max }(\mathrm{h})$ & $0.57 \pm 0.05$ & $0.57 \pm 0.05$ \\
$A U C(\mu \mathrm{gh} / \mathrm{mL})$ & $5.91 \pm 0.19$ & $5.20 \pm 0.14$ \\
$k_{\mathrm{el}}(\mathrm{h})$ & $0.43 \pm 0.03$ & $0.45 \pm 0.04$ \\
$t_{1 / 2}(\mathrm{~h})$ & $1.67 \pm 0.15$ & $1.59 \pm 0.14$ \\
$V d(\mathrm{~mL})$ & $324 \pm 21$ & $356 \pm 42$ \\
$C L(\mathrm{~mL} / \mathrm{h})$ & $139 \pm 14$ & $156 \pm 14$ \\
$M R T(\mathrm{~h})$ & $2.40 \pm 0.22$ & $2.29 \pm 0.21$ \\
\hline
\end{tabular}

a) $C_{\max }$, maximum drug concentration; $t_{\max }$, maximum drug concentration time; $A U C$, area under the concentration-time curve; $k_{\mathrm{el}}$, elimination rate constant; $t_{12}$, half-life period; $V d$, distribution volume; $C L$, clearance; $M R T$, mean residence time.

the results are listed in Table 2. The pharmacokinetics of nedaplatin in rats are in agreement with previously reported literature. $^{11)}$

\section{Conclusion}

We developed CLC-UV with high sensitivity for determining platinum-based antitumor drugs in rat plasma, and it was applied to determine the pharmacokinetic parameters of total and free form nedaplatin in rats by their time-concentration profiles.

Although ICP-AES, ICP-MS, and NFAAS methods are used to determine platinum-based antitumor drug, they require complicated sample preparation and cleanup procedures before analysis, whereas, the sample preparation in the present CLCUV method is very simple and easy.

Previously reported HPLC-UV methods use $0.1-6 \mathrm{~mL}$ of plasma as a sample, however, we demonstrated that $20 \mu \mathrm{L}$ of plasma were sufficient for determination of platinum-based antitumor drugs in this study. Thus, the collection of blood specimens from humans could be performed using a lancing device to prick the finger. Such a collection method would be useful from the viewpoint of bioethics to reduce the burdens on human subjects.

Moreover, by use of a capillary column in a chromatographic system, the present CLC-UV has an advantage from the points of view of economical efficiency and green chemistry because a solvent such as a mobile phase required for measurement was remarkably reduced compared with HPLC-UV using a conventional column.

In a study by Lopez-Flores et al., HPLC-UV by using the mean of DDTC derivatization was applied to determine cisplatin in a Hela cancer cell line and in tumor samples of cisplatin-treated $n u / n u$ mice. $\left.{ }^{25}\right)$ Furthermore, this application was found to be useful to evaluate the degree of intracellular accumulation of cisplatin in both cancer cells and tumor samples that could be used to identify mechanisms of cytotoxicity and/or resistance in which the drug's intracellular concentration decreases. ${ }^{34)}$ By the present CLC-UV, the determination of intracellar platinum-based antitumor drug content in a cancer cell and in tumor samples could be also performed. Moreover, many kinds of platinum-based antitumor drugs such as oxaliplatin, miriplatin, and saliplatin etc. have been developed. ${ }^{20,35-41)}$ The present CLC-UV method would be acceptable for the quantitative analysis of these platinum-based antitumor drugs.

In conclusion, the present CLC-UV is a highly sensitive, accurate, and precise, method for the determination of platinum-based antitumor drugs in plasma, and it could be useful in further pharmacological, pharmacokinetic, and clinical studies.

\section{References}

1) Kato H., Fukuchi M., Manda R., Nakajima M., Miyazaki T., Sohda M., Masuda N., Fukai Y., Tsukada K., Kuwano H., Anticancer Res., 23, 3493-3498 (2003).

2) Yamada H., Maki H., Takeda Y., Orita S., Anticancer Res., 26 (2A), 989-994 (2006).

3) Yamashita H., Nakagawa K., Tago M., Igaki H., Nakamura N., Shiraishi K., Sasano N., Ohtomo K., Dis. Esophagus, 19, 15-19 (2006).

4) Kuwahara A., Yamamori M., Nishiguchi K., Okuno T., Chayahara N., Miki I., Tamura T., Inokuma T., Takemoto Y., Nakamura T., Kataoka K., Sakaeda T., Int. J. Med. Sci., 6, 305-311 (2009).

5) Hamada Y., Naitoh H., Niibe Y., Kotani A., Takayanagi R., Tsunoda S., Unno N., Hayakawa K., Kusu F., Yago K., Yamada Y., Eur. J. Gynaecol. Oncol., 31, 517-521 (2010).

6) Mustonen R., Hemminki K., Alhonen A., Hietanen P., Kiilunen M., IARC Sci. Publ., 89, 329-332 (1988).

7) Mustonen R., Hietanen P., Leppälä S., Takala M., Hemminki K., Arch. Toxicol., 63, 361-366 (1989).

8) Andrews P. A., Wung W. E., Howell S. B., Anal. Biochem., 143 46-56 (1984).

9) Bannister S. J., Sternson L. A., Repta A. J., J. Chromatogr., 173, 333-342 (1979).

10) Kizu R., Yamamoto T., Yokoyama T., Tanaka M., Miyazaki M., Chem. Pharm. Bull., 43, 108-114 (1995).

11) Sugeno K., Mizojiri K., Okabe H., Esumi Y., Takaichi M., Okada Y., Iyakuhin Kenkyu, 22, 231-242 (1991).

12) Nakamura M., Koshida H., Kawabata T., Miyata K., Yamamoto K., Iyakuhin Kenkyu, 22, 612-625 (1991)

13) Sugeno K., Mizojiri K., Okabe H., Esumi Y., Takaichi M., Shibusawa K., Iyakuhin Kenkyu, 22, 901-910 (1991).

14) Yamamoto N., Tamura T., Kurata T., Yamamoto N., Sekine I., Kunitoh H., Ohe Y., Saijo N., Cancer Chemother. Pharmacol., 65, 79-88 (2009).

15) LeRoy A. F., Wehling M. L., Sponseller H. L., Friauf W. S., Solomon R. E., Dedrick R. L., Litterst C. L., Gram T. E., Guarino A. M., Becker D. A., Biochem. Med., 18, 184-191 (1977).

16) Ferron G., Dattez S., Gladieff L., Delord J.-P., Pierre S., Lafont T., Lochon I., Chatelut E., Cancer Chemother. Pharmacol., 62, 679-683 (2008).

17) Morazzoni F., Canevali C., Zucchetti M., Caroli S., Alimonti A., Petrucci F., Giudice G., Masoni E., Bedini A. V., J. Cancer Res. Clin. Oncol., 124, 37-43 (1998).

18) Gammelgaard B., Hansen H. R., Stürup S., Møller C., Expert Opin. Drug Metab. Toxicol., 4, 1187-1207 (2008).

19) Falta T., Koellensperger G., Standler A., Buchberger W., Mader R. M., Hann S., J. Anal. At. Spectrom., 24, 1336-1342 (2009).

20) Su Q., Liu Q., Luo G., Liu W., Yu Y., Wang Y., Bi K., Drug Dev. Ind. Pharm., 34, 472-477 (2008).

21) Smith C. J., Wilson I. D., Abou-Shakra F., Payne R., Parry T. C., Sinclair P., Roberts D. W., Anal. Chem., 75, 1463-1469 (2003).

22) Ding H., Goldberg M. M., Raymer J. H., Holmes J., Stanko J., Chaney S. G., Biol. Trace Elem. Res., 67, 1-11 (1999).

23) Lanjwani S. N., Zhu R., Khuhawar M. Y., Ding Z., J. Pharm. Biomed. Anal., 40, 833-839 (2006).

24) Khuhawar M. Y., Arain G. M., Talanta, 66, 34-39 (2005).

25) Lopez-Flores A., Jurado R., Garcia-Lopez P., J. Pharmacol. Toxicol. Methods, 52, 366-372 (2005).

26) Iwabuchi H., Nagashima H., Nakamura K., Bunseki Kagaku, 37, 88-93 (1988). 
27) Terashima C., Tanaka H., Furuno M., J. Chromatogr. A, 828, 113120 (1998).

28) Kotani A., Takahashi K., Hakamata H., Kojima S., Kusu F., Anal. Sci., 23, 157-163 (2007).

29) Ito S., Ishida Y., Nippon Rinsho, 68 (Suppl. 1), 301-304 (2010).

30) Hatano S., Nishi Y., Usui T., Am. J. Clin. Nutr., 35, 120-126 (1982).

31) Tomita H., Tanaka M., Ikui A., Biomed. Res. Trace Elements, 18, 54-62 (2007).

32) Yoshihara K., Fukunaga K., Yoshida M., Trace Nutr. Res., 24, 120-123 (2007).

33) Abe M., Matsuda Y., Komura N., Fukunaga K., Arakawa Y., Yoshida M., Trace Nutr. Res., 25, 46-50 (2008).

34) Kartalou M., Essigmann J. M., Mutat. Res., 478, 23-43 (2001).

35) Mansuri-Torshizi H., Ghadimy S., Akbarzadeh N., Chem. Pharm.
Bull., 49, 1517-1520 (2001).

36) Kouroussis C., Souglakos J., Kakolyris S., Mavroudis D., Malamos N., Kalbakis K., Androulakis N., Agelaki A., Vardakis N., Samonis G., Georgoulias V., Oncology, 61, 36-41 (2001).

37) Hah S. S., Henderson P. T., Turteltaub K. W., Bioorg. Med. Chem. Lett., 20, 2448-2451 (2010).

38) Kawai H., Kitano Y., Mutoh M., Hata G., Chem. Pharm. Bull., 41, 357-361 (1993).

39) Shimakura J., Fujimoto K., Komuro S., Nakano M., Kanamaru H., Xenobiotica, 32, 399-409 (2002).

40) Hanada M., Baba A., Tsutsumishita Y., Noguchi T., Yamaoka T., Cancer Sci., 100, 189-194 (2009).

41) Liu W., Qing C., Chen X., Ye Q., Yu Y., Hou S., Chem. Pharm. Bull., 56, 659-662 (2008). 